\title{
Introduction of Techniques Reducing Construction Waste
}

\author{
Rui song. Pan ${ }^{1}$, Dong hai Xie ${ }^{1}$, Hua Ying Zhang ${ }^{2}$ \\ ${ }^{1}$ ShanDong Urban Vocational College Jinan, China \\ ${ }^{2}$ Shan Dong Jian Zhu University, Jinan, China
}

\begin{abstract}
In large-scale urban adaptation and real estate development process, some protective cultural relic buildings and modern excellent architecture face the reality of being demolished, that will produce a large number of construction rubbish, pollute the environment, at the same time, cause a large number of resources waste. In this paper, the application of monolithic moving technique of building is introduced, which can not only save nature resources, but also maximum reduce pollution to the environment.
\end{abstract}

Keywords: Technique; Reduce; Building waste

\section{Introduction}

The rapid development of our economy and quickly development of the progress with town building, cause the infrastructure construction scale is much bigger in China. During large-scale urban planning process, a lot of newer buildings that have perfect functions facing demolition. It brings a series problem of nature resources consumed, pollution of the environment, energy consumes and the problem of continual development while tearing down the building, as shown on Fig.1, Fig.2. In order to solve those problem, civil engineer provided a good processing way -- buildings translation technology, which will be benefit to protect natural resources and maximum reduce the negative effect on natural environment.

The integral building translation technology first applied in New Zealand, engineers use steam locomotive as draught device and moved masonry of New Plymouth to a new location. In 1901, in American Iowa university, one threestories museum had been overall translated because campus extension. In 1998, one luxurious villa was shift from city Boca to the city Peace, the juniors trek more than 100 miles.

Since the early 1980s building migration technology emerges in China, more than one hundred of building had been integral moved successful. These cases including frame structure, brick and concrete structure, bricks timberwork, and even a composite structures. Displaced building types include residential, office, hotel, memorial and cultural buildings, also have Bridges, etc. Moving direction with vertical, horizontal, oblique and horizontally rotating. Compared with 
foreign countries, these buildings general have huge volume or larger weight, but generally shorter translation distance.

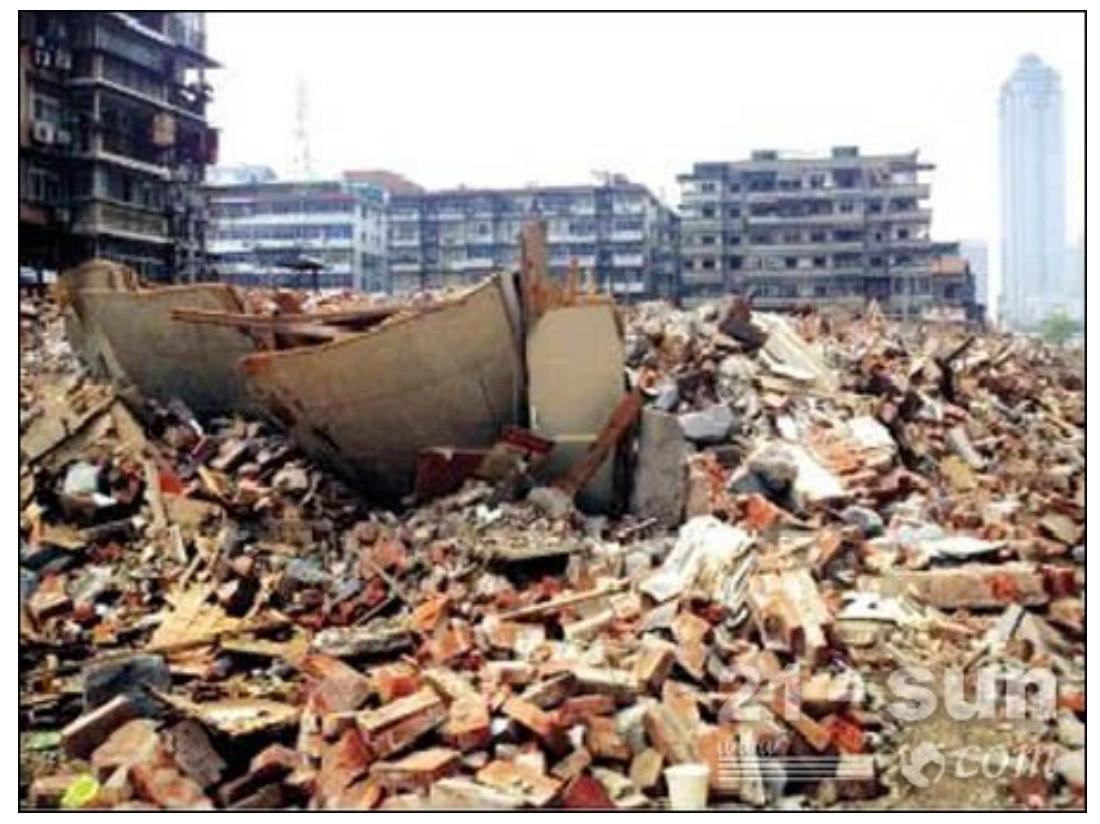

Fig.1 solid rubbish of the building

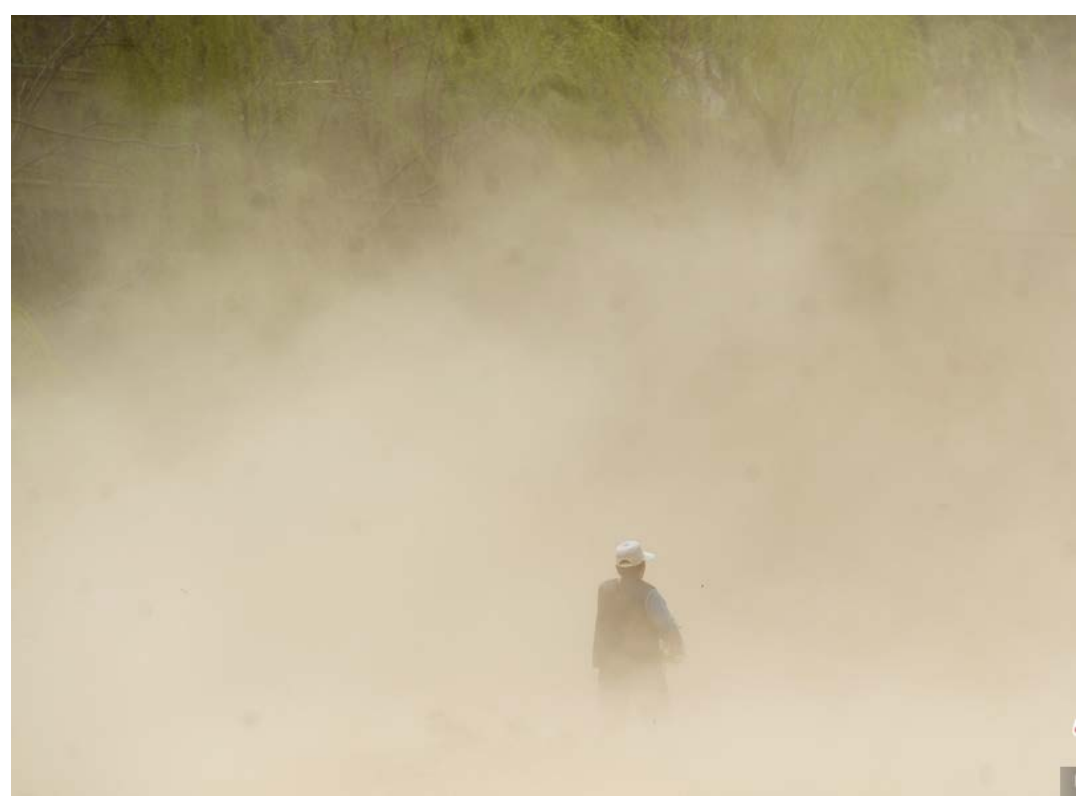

Fig.2 dust of the buiding 


\section{Integral Transition Technology}

Building whole translation means to migrate a building from one place to a new site in guarantee the building's main structure integrity and use function not be destroyed. Building shift usually contain whole translation, rotation and jackup processes. The building translation is not only higher in technical requirement, but also have certain risk during shift, that means it need to satisfy the requirement of planning and municipal administration after moving, and building structure should not be damaged, too.

In practice building integrally translation is to transfer the loads from the original foundation to a certain rigidity of bearing brackets (pallet beam), the superstructure will be cut off with the original foundation from bracket device below, then exert horizontal thrust to bearing bracket and translate the building to planning position. According to the different ways of building integrally movement, it divided into rolling shift, sliding shift and wheel plug-fuse type shift.

\section{Introduce of three shift methods}

Scroll shift refers to lay rollers between the tray beams and track girders, through the continuous rolling of rollers to realize the upper system shift. One of its advantages is small friction coefficient $(0.003 \sim 0.1)$, small migration force need to offer, the other advantage is move faster, the third is simple to construct and easy to control the moving direction. The faults are building only moves along the roller's rolling direction, and if the building has great weight may cause the section size of the underpinning component or below orbit increase evidently. There are two ways to layout the rollers, one is riddled with and the other is local decorates, shows in Fig.3. To wall bearing structures, riddled with type can be chose. In this scheme, roller bearing is lesser and internal force of the underpinning beam is lesser also. For column bearing structure, local arrangement type should be chose priority. Rollers should have the ability to resist deformation of certain degree. Currently, steel bar roller, seamless steel tube perfuse with highstrength expansion concrete roller, seamless steel tube perfuse with polymer roller and engineering plastics alloy roller etc, are used widely.
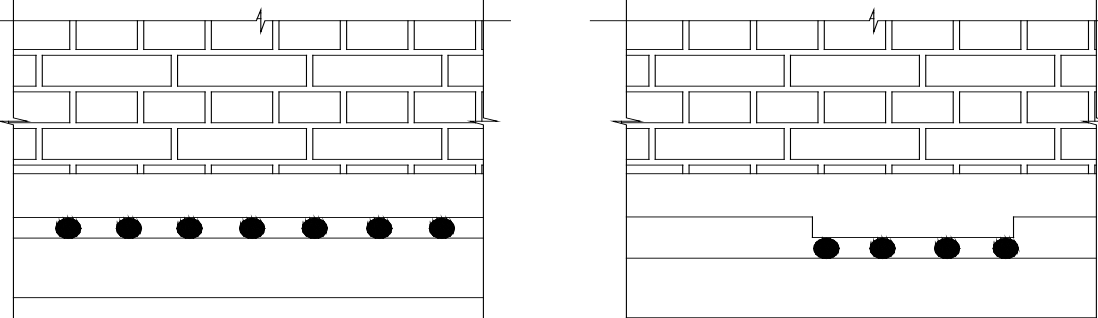

a) Roller integrity layout

b) Roller local layout

Fig.3 Schedule of Two Kinds Roller layout 
For sliding shift(been used in the Hong Ji Tang shifting as shown in Fig. 4 ), Teflon slider is placed between the slide surfaces of up- down track girder, and force is applied to make the building sliding relative to the track to achieve the purpose of building translation. Teflon slider have excellent friction performance, and can be used from - $180 \quad$-Qrm.260 foe isantongime, its chemical stability is well, not reaction with strong acid and aqua regia even at high temperatures; Electrical insulation is good, not affected by environmental condition, temperature and frequency influence; Resistance to atmospheric aging performance is good, expose to atmosphere, surface and performance remains unchanged.

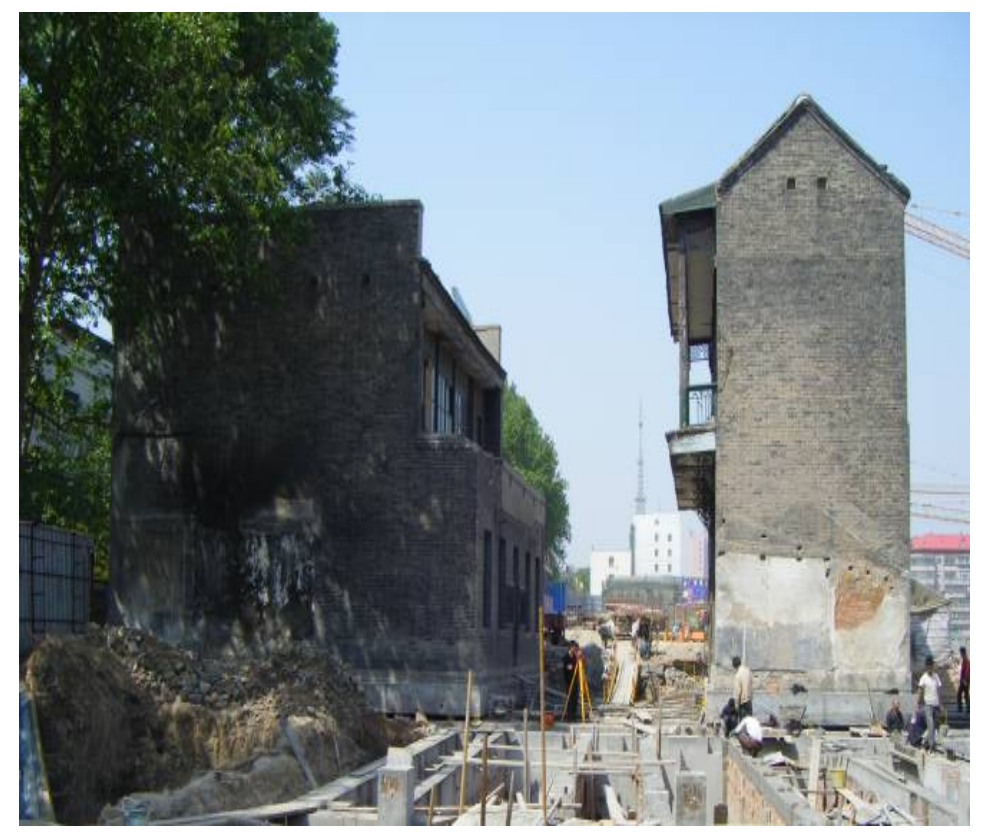

Fig.4 Hong Ji Tang shifting by Teflon sliders

Lubrication performance is good, static friction coefficient is about 0.04, it has the lowest friction coefficient to the sliding surface materials in use. Some special researches for the frictional coefficient that have given the frictional coefficients range. Teflon slider is easy to transfer to the metal surface, easy to mechanical processing. The advantages of sliding shift are moving smooth, shock resistant and wind resistant well. It had been used in the Shan Dong Fengda Bank as shown in Fig.5. The traditional device of sliding shift exist defect of big translations resistance, in order to solve the problem, an internal force controllable sliding bearings is developed in recent years, thus it can effectively avoid the influence of orbital roughness and slider failure to superstructure, due to its cost is expensive and computer control system demand is higher, it is suitable for load larger and high-rise buildings translation. 


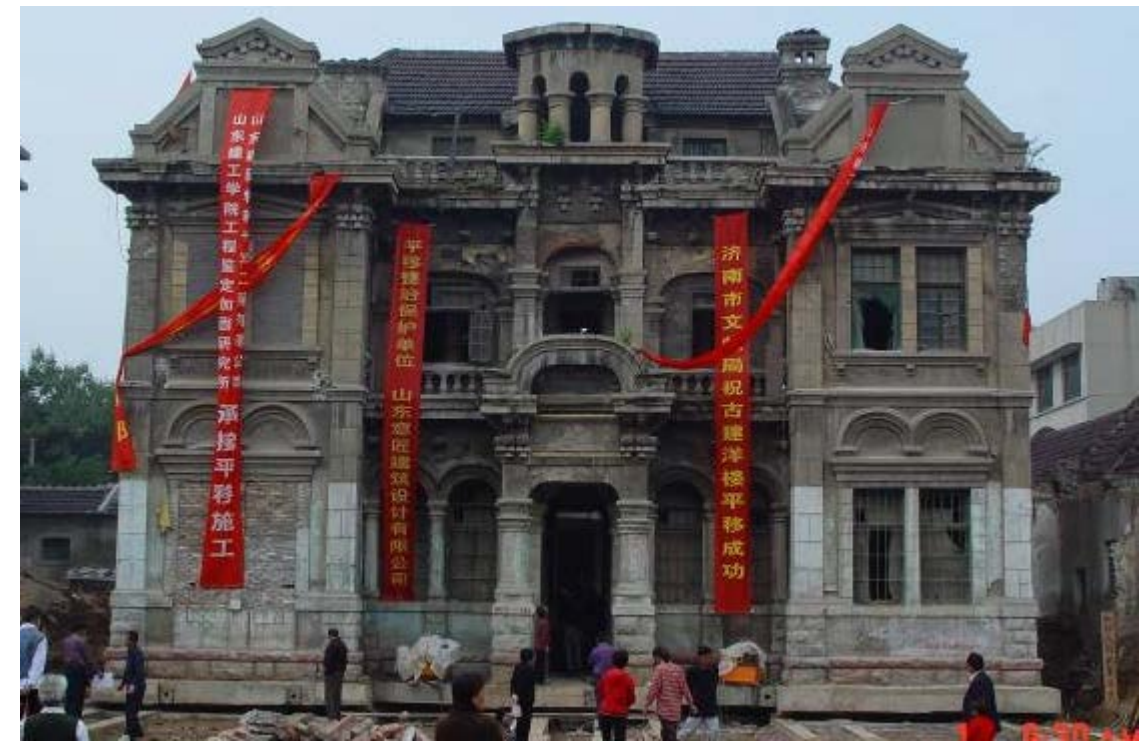

Fig.5 Shan Dong Fengda Bank shifting by steel rollers

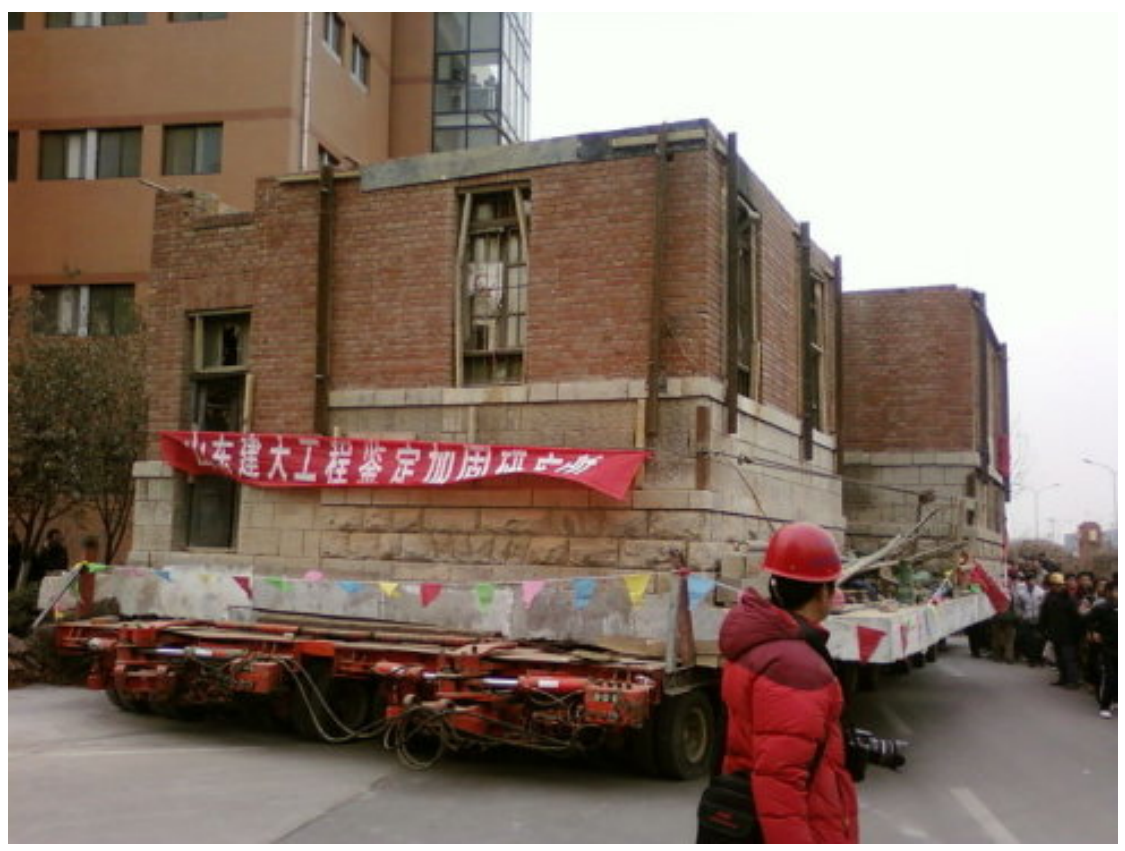

Fig.6 Old Villa shifting by Flat Bed Trailer 


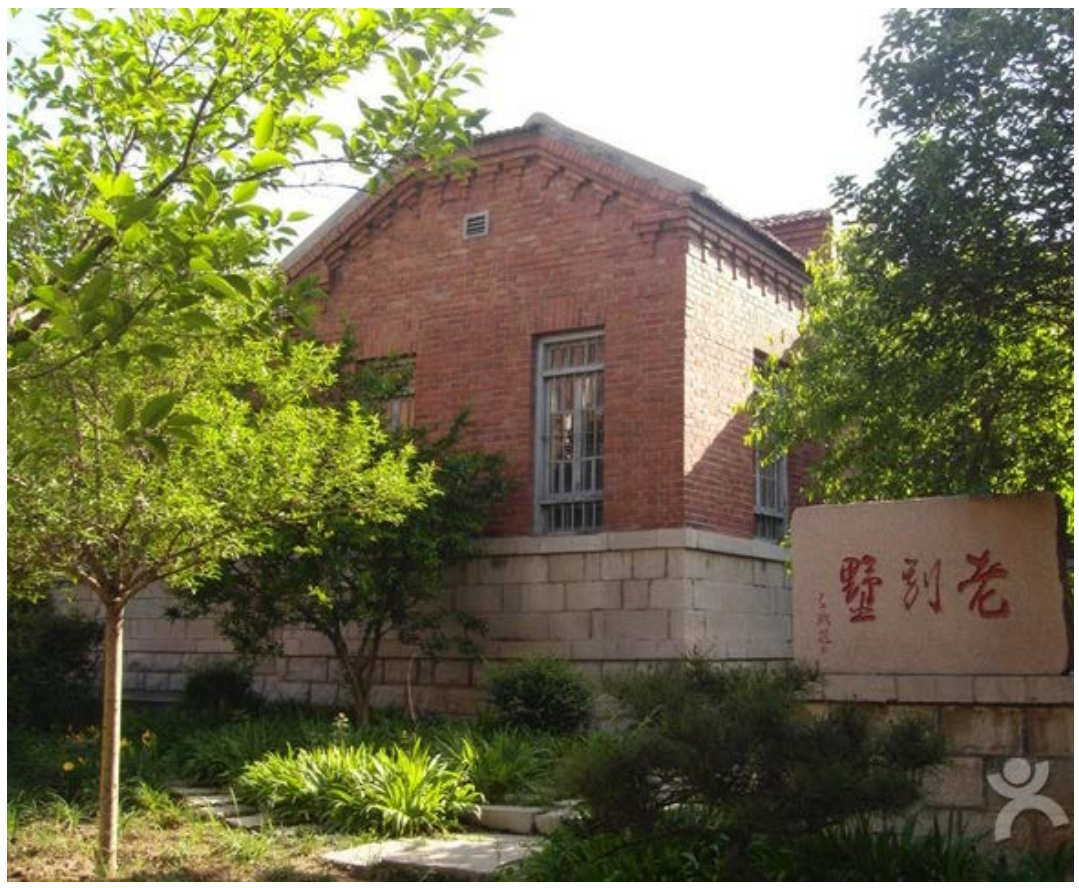

Fig.7 Old Villa on the new location

Wheel plug-fuse type shift() is transfer buildings upon a special kind of flat bed trailer, to achieve the aim of buildings shift. This method is suitable for longdistance shift also for building load smaller translation project. An old villa had been moved 25 kilometers adopt this shift mode by Shandong Jianzhu University in Jinan City as shown in Fig. 6,7.

\section{Translation technology for environmental protection contribution}

Building integrally translation technology includes the following basic content:

1. The construction of buildings based in planning and shift track girder;

2. Underpinning construction on the top face of the original building foundation. Pouring concrete beam under the main wall and column or pouring concrete beam on both sides, forming reinforced concrete underpinning chassis, it can strengthen the upper structure at the same time can be used as the up-track beam of moving.;

3. Laid steel plate on the original foundation top and track girder top of the building.;

4. Arrange the steel roller or sliding bearings on steel plate; 
5. Separate the upper structure with foundation, and then place the sup structure on roller or sliding bearings;

6. Exert traction force, and then shift the separated buildings along the track to the appointed place;

7. Connected the main wall and column with new base reliable, and do some necessary reinforcement;

8. Restore indoor ground, and make necessary decorate;

It can be seen from the context of the building whole translation, there are almost no construction waste appears as meeting the architectural planning, the influence to environmental is decreased to the minimum. Therefore we can say that in the urban construction taking full advantage of buildings using life and appropriate use of building integrally translation technology, not only can save nature resources, but also maximum reduced pollution to the environment. It is an important part of strategy of sustainable development.

\section{Conclusions}

This paper introduces a way to avoid construction waste emergence, namely building integrally translation technology. Many engineering example had proved the advantages of this technique, by this method, not only meets the planning needs, but also avoid produces construction waste in the process of the building demolition, minimize the impact and damage to environment, realize the intensive development purposes of social. Building integrally translation technology will make significant contributions in environmental protection and resources health safeguard.

\section{Acknowledgements}

Project supported by "the Research Award Fund for Outstanding Young Teachers in Higher Education Institutions of Shan Dong Province 2013” and thanks for the financial aid of the Doctor' Funding of Shan Dong Jianzhu University(2012-XNBS1210).

\section{References}

[1] Lsmar Kay, Pan Deitz and Stan Barber, University of IOWA Work. The structure mover. 1999, 17(1)

[2] Kim Brownie, From Boca Raton to Fort Pierce. The structural mover. 1999, 17(1)

[3] Etalco. The Shubert theater was self-propelled. The structural mover. 1999, $17(2)$

[4] Zhang Ming; Chen Jiming; Integral Horizontal Displacement and Renovation for Shanghai Concert Hall Architectural Journal, 2005.11 pp10-12

[5] Zhang Xin; Liu Tao; Dong Hua "Translating Conservation and Strengthening of Historic Buildings in Jinan” Industrial Construction 2010 S1 pp243-246 
[6] LU Jisong; WANG Zijun; LIU Xia; SUN Renlou "Summary of energy efficient structure system”. New Building Material 20105 pp.29-32.

[7] Zhang Xialing "Study on The Green Architecture System". Journal of Chongqing Jianzhu University (Social Science Edition) 2010 pp.50-52.

[8] Liu Wei "The Research on the Life Cycle Cost of the Green Architecture”.2009 Chong Qing University Master Paper

[9] Liu Hongyan "The Influence of Construction Engineering on Environment and Analysis of Reasons”. 201024 pp.63-66.

[10] Sun Jie, Liao Haifeng. "Development of Green High Performance Concrete for Sustainable Development”. Journal of Disaster Prevention and Mitigation Engineering 2010 S1 pp.89-91. 